\title{
Intelligent and integrated RFID (II-RFID) system for improving traceability in manufacturing
}

\author{
Ke-Sheng Wang
}

Received: 12 December 2013/ Accepted: 14 January 2014/Published online: 11 February 2014

(C) Shanghai University and Springer-Verlag Berlin Heidelberg 2014

\begin{abstract}
In the wake of globalization, many modern manufacturing companies in Norway have come under intense pressure caused by increased competition, stricter government regulation, and customer demand for higher value at low cost in a short time. Manufacturing companies need traceability, which means a real-time view into their production processes and operations. Radio frequency identification (RFID) technology enables manufacturing companies to gain instant traceability and visibility because it handles manufactured goods, materials and processes transparently. RFID has become an important driver in manufacturing and supply chain activities. However, there is still a challenge in effectively deploying RFID in manufacturing. This paper describes the importance for Norwegian manufacturing companies to implement RFID technology, and shows how the intelligent and integrated RFID (II-RFID) system, which has been developed in the Knowledge Discovery Laboratory of Norwegian University of Science and Technology, provides instant traceability and visibility into manufacturing processes. It supports the Norwegian manufacturing industries survive and thrive in global competition. The future research work will focus on the field of RFID data mining to support decision-making process in manufacturing.
\end{abstract}

\section{K.-S. Wang $(\bowtie)$}

Shanghai Key Laboratory of Intelligent Manufacturing and Robotics, Shanghai University, Shanghai 200072, People's Republic of China

e-mail: kesheng.wang@ntnu.no

K.-S. Wang

Knowledge Discovery Laboratory, Department of Production and Quality Engineering, Norwegian University of Science and Technology, N-7491 Trondheim, Norway
Keywords Radio frequency identification (RFID) . Intelligent manufacturing - Traceability · Visibility . System integration · Intelligent decision support systems

\section{Introduction}

Globalization is a strategy for modern manufacturing companies in Norway. They have come under intense pressure due to harder competition, more extensive geographic footprint, stricter government regulation and the demand for higher value at low cost in a short time. Manufacturing companies need traceability more than ever, which is a realtime view into their operations and processes. Traceability in manufacturing helps manufacturing ensure compliance with government regulations; better protects its brand and consumers; and performs rapid, focused and cost-effective product tracking and tracing that minimize financial impact.

In recent years, radio frequency identification (RFID) technology has moved into the ranks of disruptive information and communication technology (ICT) that supports the handling of manufactured goods, materials and processes. The implementation of RFID may be linked with significant improvement in the business of a company. Especially, RFID has become an important driver in production and supply chain activities. It offers the capability of automatic and accurate object data capturing and enables instant traceability and visibility [1]. RFID technology is applicable in many areas such as manufacturing, supply chain, logistics, libraries and agriculture. However, how to deploy a complete RFID system in manufacturing is still a challenge [2]. An integrated RFID system with intelligent decision support is necessary for increasing productivity of manufacturing company. There is still lack of researches in this field and few papers have been discussed about it. 
This paper describes how we develop the intelligent and integrated RFID (II-RFID) system, which provides real-time traceability and visibility into manufacturing processes. It has been tested in some Norwegian companies [3]. In addition, it identifies the implementation areas where RFID technology has had the greatest impact and explains why it is so important to develop a traceability system.

\section{Traceability in manufacturing}

\subsection{What is traceability?}

According to ISO 8402, traceability is defined as "the ability to trace the history, application or location of an entity by means of recorded identifications". For discrete manufacturers, it means you can track and trace each component that comprises your product-from suppliers and manufacturers through assembly and final delivery to customers by creating an as-built genealogy. For food and other process manufacturers, it is the ability to trace each ingredient of a product from "farm to fork" through the creation of a batch genealogy. There are multiple ways that can be accomplished including using technologies such as direct part marking for discrete manufacturers, where parts and components receive a permanent mark either as they enter assembly or by suppliers. The most common methods for applying permanent marks include dot peen, laser etching, molding and stamping, or casting. Other technologies that enable traceability for all manufacturing types include 1D and 2D bar codes and RFID. Once you have chosen a traceability method, you can determine which global trade item number (GTIN), lot or serial level identification is needed based on your operations.

\subsection{Why is traceability the next great challenge in manufacturing?}

Let us take as an example a project run in a company CLU (Slides Clutch) located in Germany which manufactures sliding clutches and assembles sliding clutches for drive trains in automobiles. The main goal of the project is to narrow the scope of possible recalls and to reduce resulting costs. If a production error is detected, all clutches that are potentially affected must be checked manually. If those faulty products are already shipped, checks must even take place at the customers' locations. This results in additional costs for sending workers to the customers. The costs for recalls are higher for clutches that are already used in a customer's production. In this case, CLU must pay penalties. These penalties amount to about $1.5 \%$ of CLU's total business volume [4], which could be a substantial sum!
Finding out exactly how, where, and when something was made is more complicated than it has ever been because the production line is increasingly international and decentralized. Most of the things we make and use come cheaper, faster, and farther than ever. Consumers who want to behave responsibly for myriad reasons struggle with this, but so do companies. The problem and its solution can be boiled down to one thing: traceability.

Traceability demands accurate accounting in manufacturing-knowing all you can know about the components you are working with so that you can identify problems and inefficiencies in your production line quickly and fix them before they multiply. Many companies, like BMW, do not own all the subsidiaries that make parts going into their products, therefore accurate accounting has big implications.

Because of the high cost for supplementary checks and penalties, reducing recalls holds the potential for significant savings. Costs for recalls can be reduced if tracking information facilitates narrowing the scope for inspections. Recoding tracking information with RFID and analyzing this tracking information will help limit the scope of recalls and checks. Eventually all plastic pallets carrying material parts will be equipped with RFID tags, and suppliers will provide information about the shipment by using rewritable RFID tags.

\subsection{How to enable traceability in manufacturing?}

RFID is one of numerous technologies grouped under the term of automatic identification (auto ID), such as bar codes, magnetic inks, optical character recognition, voice recognition, touch memory, smart cards, biometrics, etc. Auto ID technology is a new way of controlling information and material flow, especially suitable for large production networks. RFID is a wireless non-contact radio system, which transfers data from a tag attached to an object, for the purposes of identification and tracking. The technology can be used to identify, track, sort or detect a wide variety of objects [5, 6]. RFID systems can be classified by the working frequency, i.e., low frequency (LF), high frequency (HF), ultra high frequency (UHF) and microwave. Different frequencies work for various media, e.g., UHF is not applicable to metal but HF is metal friendly. Thus, the working frequency has to be determined on the basis of the tracked objects [7,8].

Hardware for a RFID system includes RFID tag, RFID reader and RFID antenna. RFID tag is an electronic device that can store and transmit data to a reader in a contactless manner using radio waves, which can be read-only or readwritten. Tag memory can be factory or field programmed, partitionable, and optionally permanently locked, which enables the users to save customized information in the tag and read it everywhere, or retire the tag when it will not be 
used anymore. Bytes left unlocked can be rewritten over more than 100,000 times, which results in a long useful life. Moreover, the tags can be classified by power methods, i.e., passive tags without power, semi-passive tags with battery, and active tags with battery, processor and I/O ports. The power supply increases the cost of the tag but enhances the readable performance. Middleware is required as a platform for managing acquired RFID data and routing it between tag readers and other enterprise systems. Recently, RFID is an interesting technology in many fields such as agriculture [9], manufacturing [10] and supply chain management [6]. Combining RFID with data mining (DM) approaches increases the research fields including object tracking [11], customer purchasing behaviour analysis [12], supply chain management [13] and outlier detection [14].

Manufacturing industries have also made practical progress $[15,16]$. Manufacturers deploy RFID devices to shop-floor objects such as humans, machines and materials to capture data associated with their statuses [17, 18]. Such RFID-enabled real-time visibility and traceability substantially improves shop-floor management in general and work-in-process (WIP) materials management [19].

A new research direction within the field of RFID in manufacturing is to use artificial intelligence (AI) and DM technologies to analyze and interpret the huge volume of RFID data to discover hidden knowledge in order to support business decision-making [20, 21]. An important strategy for encouraging manufacturing companies is to develop a practical II-RFID system rather than only using RFID for manufacturing data collection. The following section will present the framework of II-RFID system which has been developed in the Knowledge Discovery Laboratory (KDL) at Norwegian University of Science and Technology (NTNU).

\section{II-RFID system}

With the development of the RFID technique, it becomes increasing possible to acquire real-time production data. However, it is far from sufficient for the company only to collect the massive amounts of RFID data and do the track and query. RFID data-based decision-making provides more value to the company and improves the production efficiency. Thus, an II-RFID system is proposed, which combines the RFID data acquisition with decision support based on DM.

\subsection{II-RFID system architecture}

As a highly automated data acquisition and decision support system, the II-RFID system comprises six levels as:

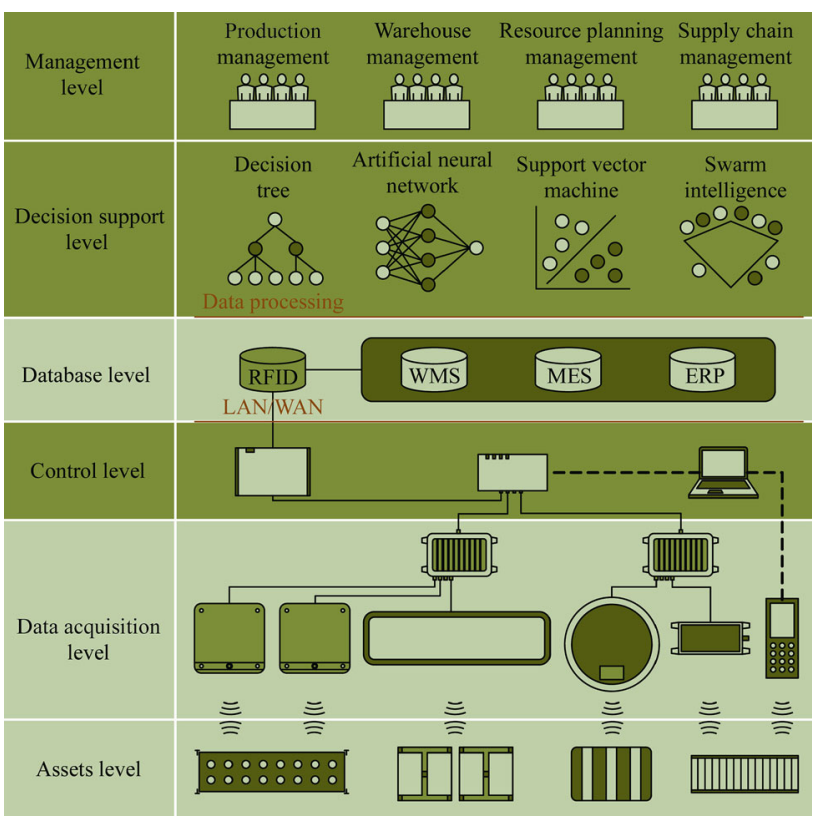

Fig. 1 System architecture of II-RFID system

(i) assets level, which contains products (from materials to finished goods), conveyor belts, machines, pallets, packages and shelves, etc.,

(ii) data acquisition level, which consists of RFID tags, antennas, readers and middleware,

(iii) control level, which consists of PCs, middleware and other network devices used to connect the equipment,

(iv) database level, which combines RFID database and other high level databases,

(v) decision support level, which involves DM approaches or computational intelligence for decision making, and

(vi) management level, which is the intended final endpoint for the construction of an II-RFID system.

As shown in Fig. 1, an II-RFID system includes the company assets, the RFID system, the production management system and the decision support system. The final goal of the II-RFID system is to discover knowledge from RFID data for the manager as a reference.

\subsection{Functions of the II-RFID system}

The II-RFID system works on the foundation of the realtime collected RFID tag information. The following tasks based on RFID data acquisition can be achieved: online part information collection, online processing progress statistics, daily processing capacity statistics per station, total processing time for a batch of product and processing time of each working process, production progress visualization and remaining processing time prediction, and quality statistics (including scrap and recall). 


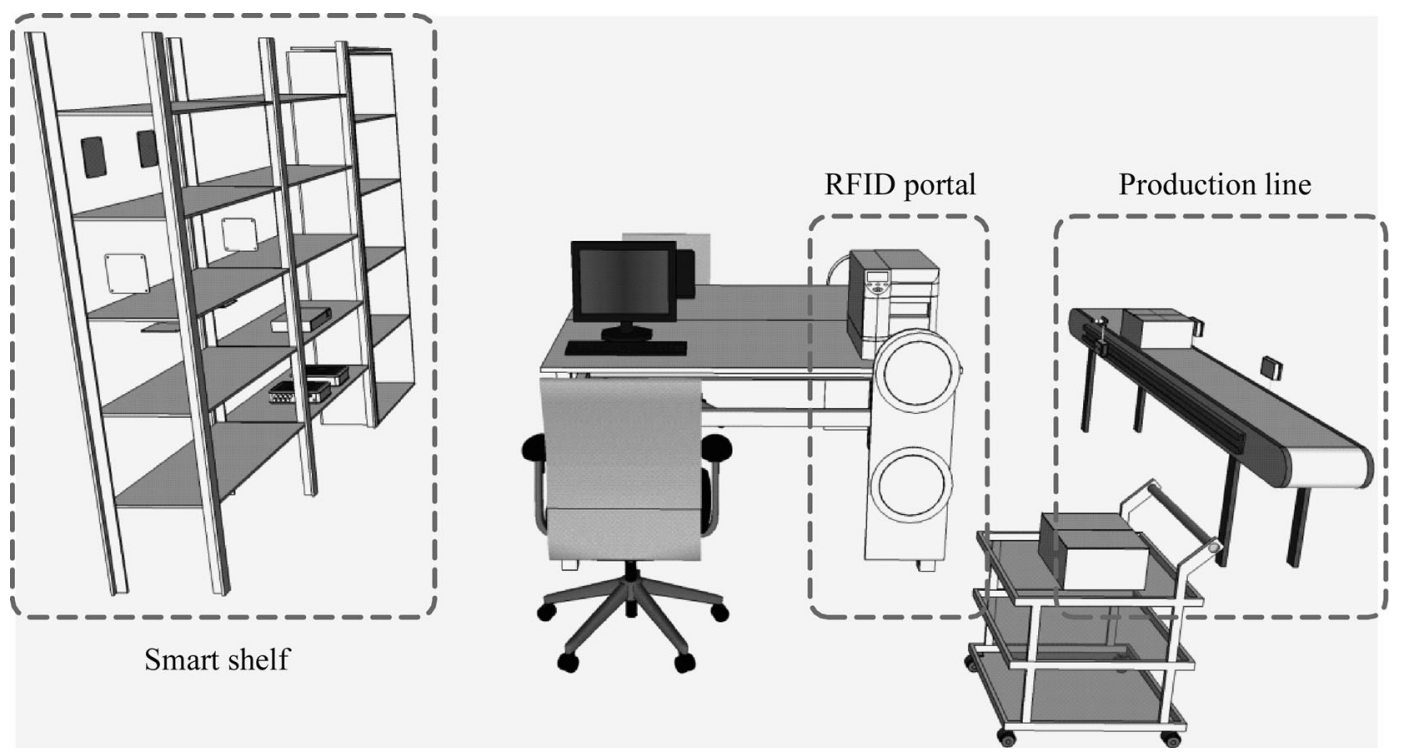

Fig. 2 RFID lab layout

Considering production management in the II-RFID system for instance, the main functions of the RFID production management system include WIP management, processing station management, manufacturing process management, production task management, personnel management and tool/fixture management. Typical data collection and reporting include the following.

(i) WIP management: WIP registration, WIP inspection registration, quality query, product positioning and tracking, prediction of the remaining processing time.

(ii) Processing station management: processing station registration, WIP of processing station query, processing station output query, process information query.

(iii) Manufacturing process management: manufacturing process registration and query. Manufacturing process management is the basis of production task schedule query.

(iv) Production task management: production task registration and query, production task schedule query.

(v) Personnel management: personnel registration, personnel productivity and production query.

(vi) Tool and fixture management: tools/fixtures registration, tool position allocation, maintaining proper maintenance schedule.

\section{Implementation of II-RFID system}

As described in the previous section, the II-RFID system has a multiple level system structure. In the KDL, the II-RFID system is implemented with both RFID hardware and
Table 1 II-RFID system implementation

\begin{tabular}{ll}
\hline System level & Implementation \\
\hline Asset level & $\begin{array}{l}\text { Assembly line, pallet, portal, trolley, shelf } \\
\text { RFID tag, RFID antenna, RFID reader, } \\
\text { handheld reader, router/switch } \\
\text { Middleware, computer, software }\end{array}$ \\
Control level & $\begin{array}{l}\text { Local RFID database } \\
\text { Database level }\end{array}$ \\
Decision support level & $\begin{array}{l}\text { Program on the basis of computational } \\
\text { intelligence }\end{array}$ \\
Management level & Manager, expert \\
\hline
\end{tabular}

software. The experiment equipment comprises infrastructure of a warehouse and production line, RFID data acquisition system and production management software. The layout of the RFID lab is shown in Fig. 2.

The RFID lab comprises three functional areas, which are the production line, the RFID portal and the smart shelf. Referring to the proposed II-RFID system architecture, the implementation of each system level is shown in Table 1.

Each functional area is installed with a variety of RFID antennas. One or multiple antennas are set to be one read point, to represent the location of the business step. For instance, the conveyor belt is used to represent the production line. Two antennas are assigned along the conveyor belt representing two working stations. The portal area consists of an entrance and an exit. Each portal is installed with two antennas to monitor the tagged goods passing by. The warehouse area comprises three shelves, where shelf 1 and shelf 2 are monitored by layer separately, while shelf 3 is monitored completely. 


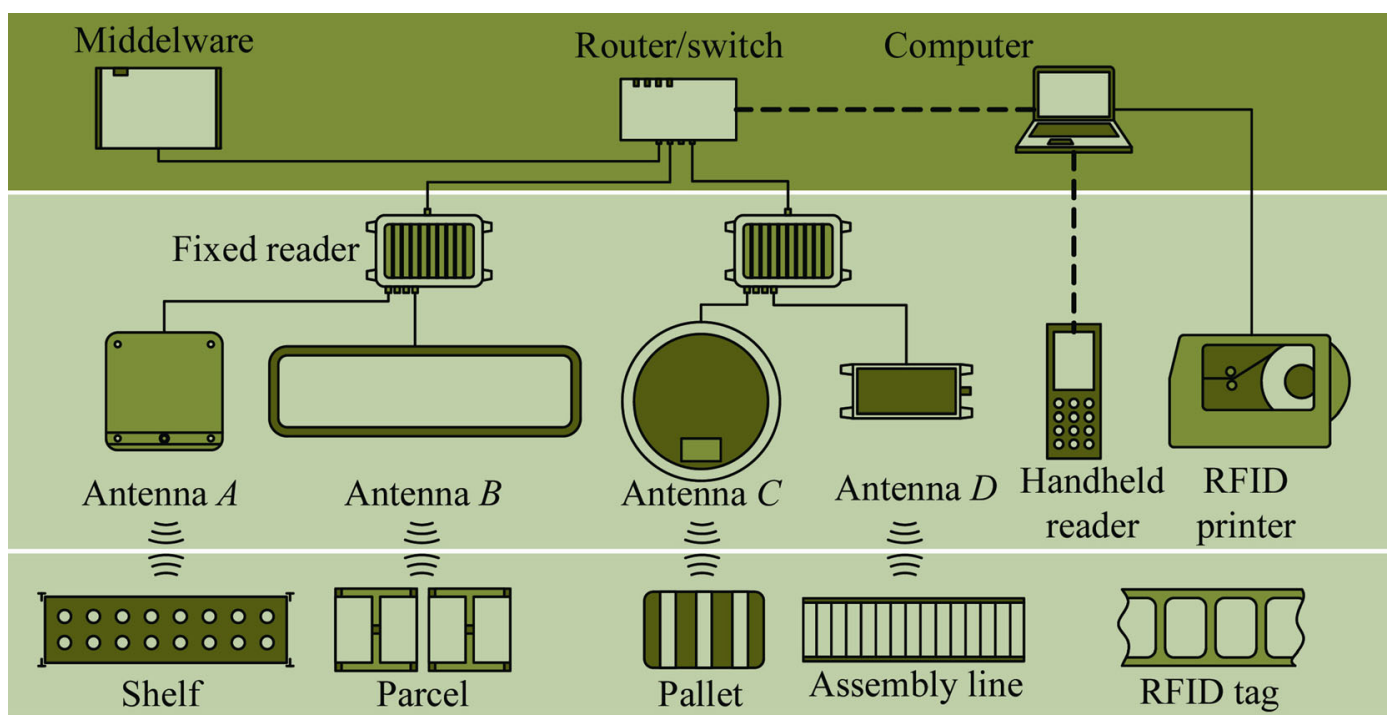

Fig. 3 Hardware in II-RFID system implementation

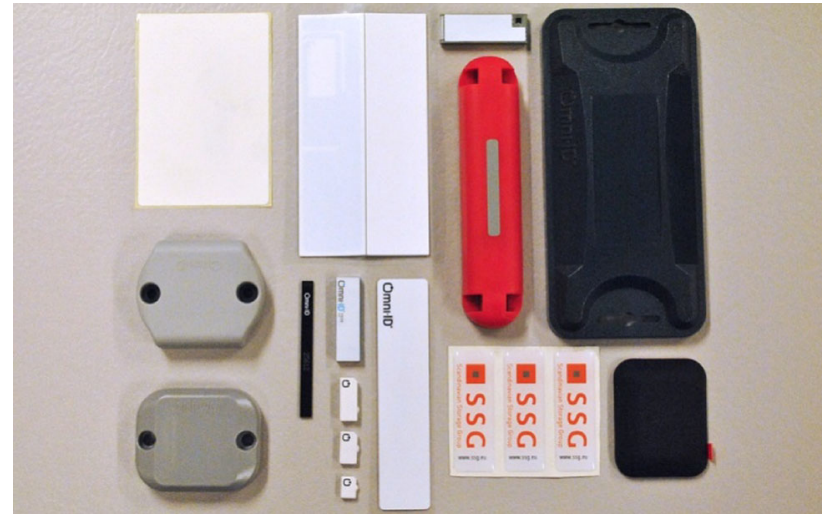

Fig. 4 RFID tags with various specifications

Thus, the RFID lab simulates RFID data collection both in the production line and warehouse, and the research will focus on production management and warehouse management.

\subsection{RFID hardware}

The physical hardware of the II-RFID system includes the assets level, the data acquisition level and part of the control level, as shown in Fig. 3. The hardware consists of the RFID printer, fixed RFID readers, reader antennas, handheld readers, middleware and other IT devices.

\subsubsection{RFID tag}

With the development of RFID technology, a variety of RFID tags have been produced to meet the various requirements. The compatibility of the RFID tag is different according to the design, which means the applicability of the tag has to be carefully considered before using it. For instance, the maximum reading distance of one tag may differ from others. Furthermore, some tags are compatible with both plastic and metal objects, while some are suitable for only one. In RFID lab, for the purpose of testing different applications, different RFID tags are prepared, as shown in Fig. 4, with varying size, maximum reading distance, material compatibility and mounting technique.

\subsubsection{RFID antenna}

Six types of RFID antennas are used in the II-RFID system implementation, as shown in Fig. 5. According to the application, antennas are deployed to read corresponding points. For instance, the near field RFID antenna made by Impinj (see Fig. 5d) is used along the assembly line to monitor the tagged pallets passing by the working station.

\subsubsection{RFID reader}

Both the fixed RFID reader and handheld reader are used in RFID lab. The fixed reader is used to power the RFID antenna and detect the RFID tag, as shown in Fig. 6. The network connection enables the reader to send the tag information to the assigned destination and receive remote tag operating command.

Figure 7 shows three types of handheld readers used in the RFID lab, which are divided into far field reader and near field reader according to the reading distance. The handheld readers integrate the RFID antenna, the RFID reader and the power supply in a single device. The handheld reader provides a portable way of detecting tags. 


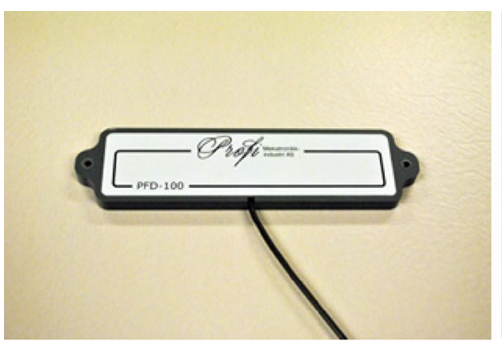

(a)

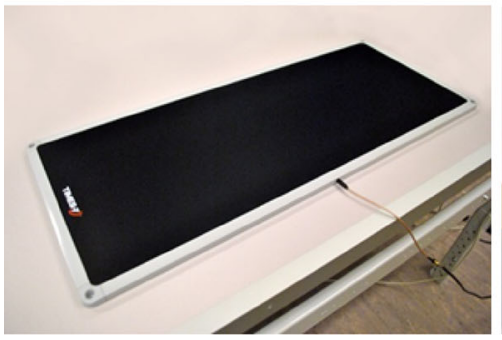

(d)

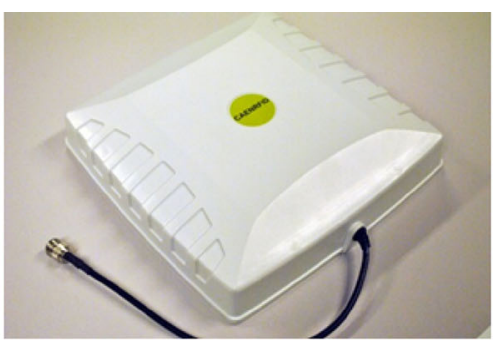

(b)

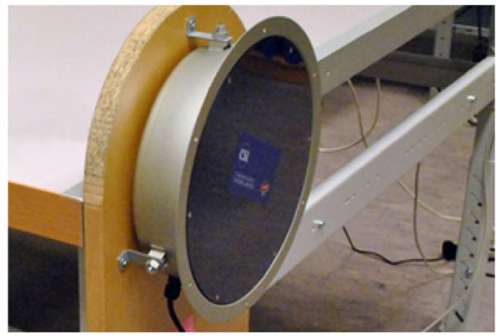

(e)

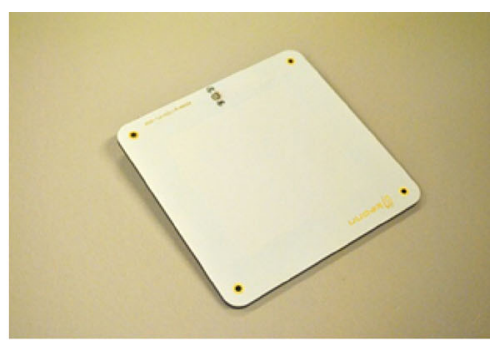

(c)

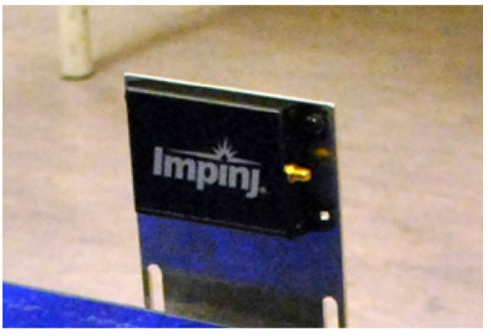

(f)

Fig. 5 RFID antennas with various specifications

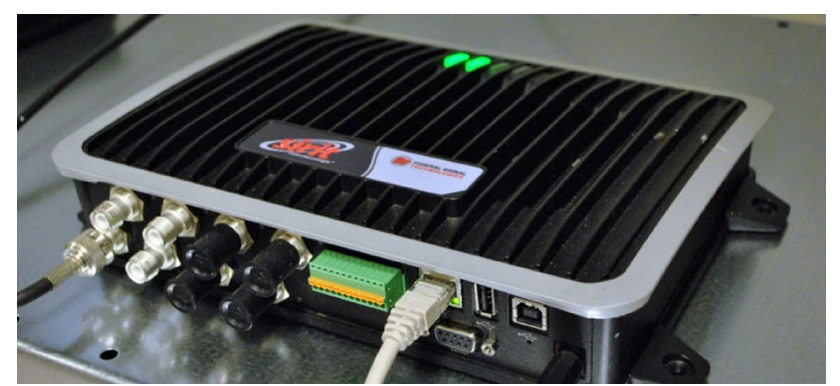

Fig. 6 Fixed RFID reader

\subsubsection{Middleware}

In II-RFID system, the middleware is used to combine realtime control of RFID readers, device and sensor management and RFID tag data processing. With the application of the middleware, the RFID tag data collected by multiple readers can be processed, organized and forwarded to the database. The middleware can be in the form of either hardware or software. The hardware used in the lab is shown in Fig. 8.

\subsection{Software}

On the basis of the hardware configuration of the II-RFID system, special software is used to configure the readers, the antennas and the middleware. Furthermore, the implementation of the RFID data management and decision support also relies on the software. This section will introduce the software used in II-RFID system in the KDL.

\subsubsection{RFID reader start-up tool}

The reader startup tool (RST) is the software of the RFID reader configuration. RST can detect and list all the readers controlled under the same network, as shown in Fig. 9.

In addition, it supports manually adding the reader by assigning the IP address of the reader. As soon as a reader is detected by RST, it is able to set the parameters of the reader including the network properties of the reader, the power of connected antennas and the detecting performance optimized for different applications.

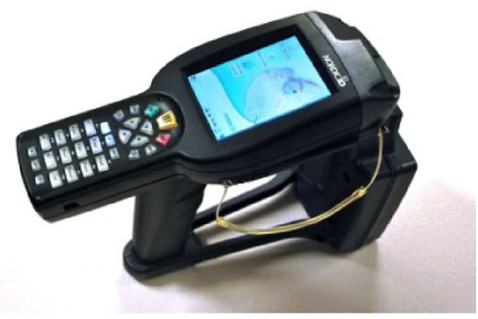

(a)

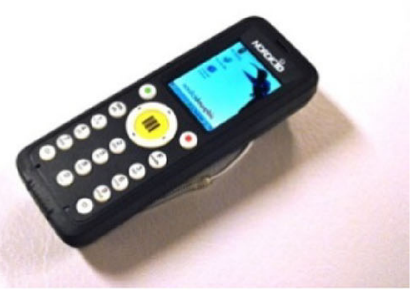

(b)

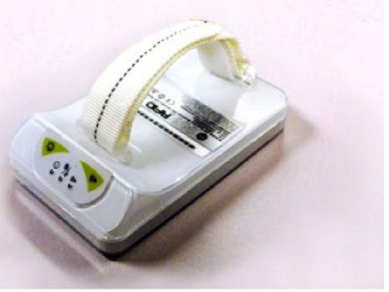

(c)

Fig. 7 Handheld readers 


\subsubsection{Middleware management console}

The middleware in the form of hardware used in the RFID lab is the product of ODIN RFID Company. The ODIN EasyTAP is used for managing and coordinating the readers, which combines real-time adaptive control of RFID readers, device and sensor management and RFID tag data processing. Figure 10 shows the interface of the middleware management reconsole.

In the middleware management console, parameters of readers and antennas are configured by auto detection and manual assignment. The emitting power of the antennas affects the signal coverage area. The working space is calibrated according to the layout reference image.

Thus, the position of the antennas can be defined with respect to the actual shop floor layout. Facility layout

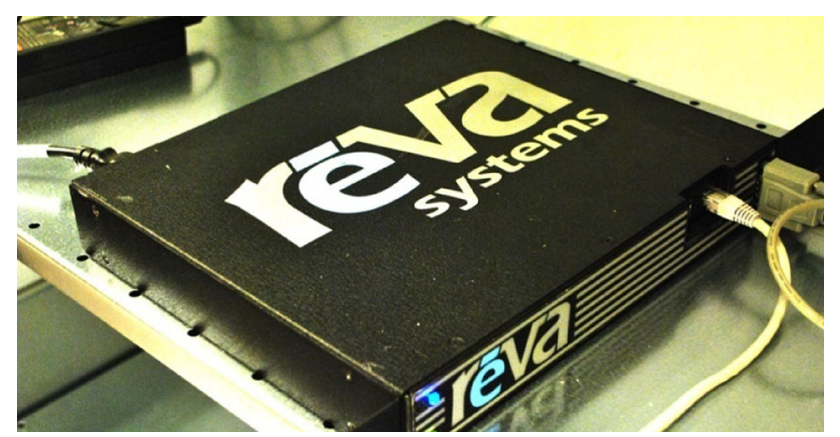

Fig. 8 RFID middleware configuration in the middleware management console is shown in Fig. 11. The RFID information collected by readers is processed by the middleware on the basis of the EPCIS standard, which carries the logistic information of the items including WHEN, WHERE, WHAT and WHY. Then it is forwarded in the form of an application level event (ALT) report to a predefined IP address representing the RFID database or the interface of other high level databases, which can be called by high level software and achieves the information sharing.

\subsubsection{RFID database}

The RFID database is set up in the local PC and receives RFID event data in the form of EPCIS report from the middleware. In the middleware configuration, a location is defined on the basis of the antennas. A location is seen as one read point and includes at least one antenna. The RFID tag can be reported when it is entering, leaving or staying at each location. Figure 12 shows the RFID data report configuration user interface. The subscriber includes the http link of the RFID database, or the interface of high level management software (WMS or ERP system) for RFID data import.

\subsubsection{Production management software}

Production management on the basis of RFID data is one of the functions of the II-RFID system. PROdog is used to

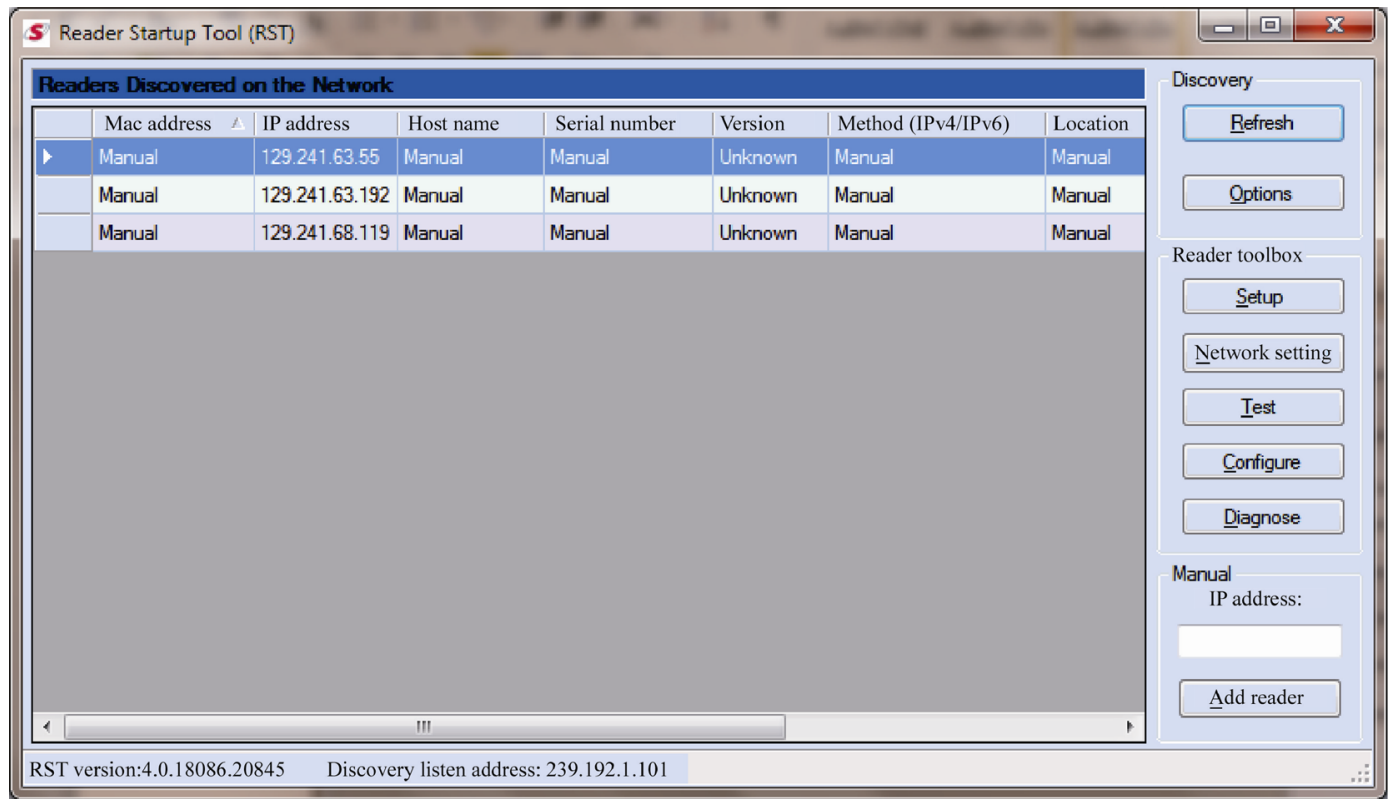

Fig. 9 Reader configuration software-Reader Startup Tool 


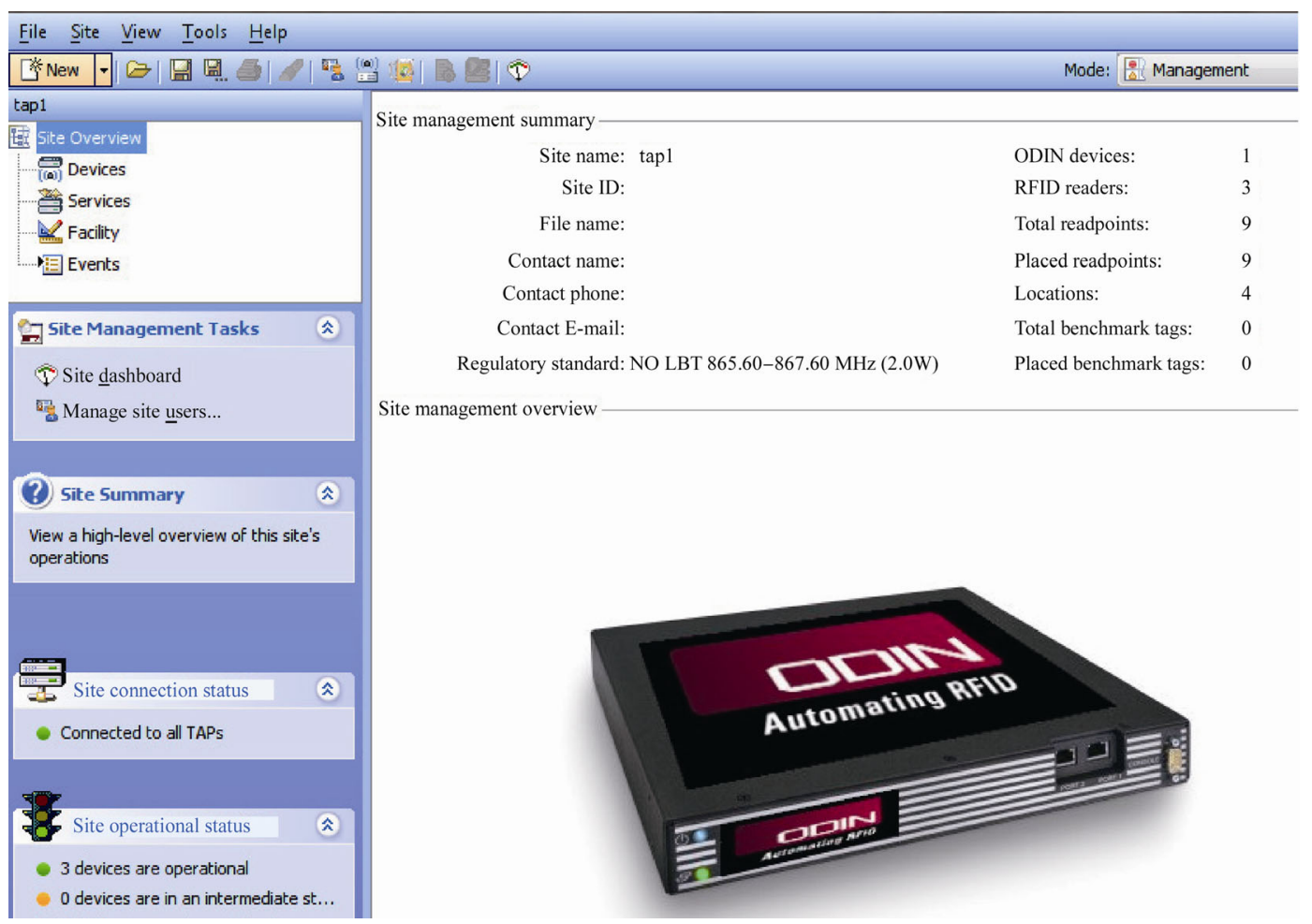

Fig. 10 Interface of the middleware management console

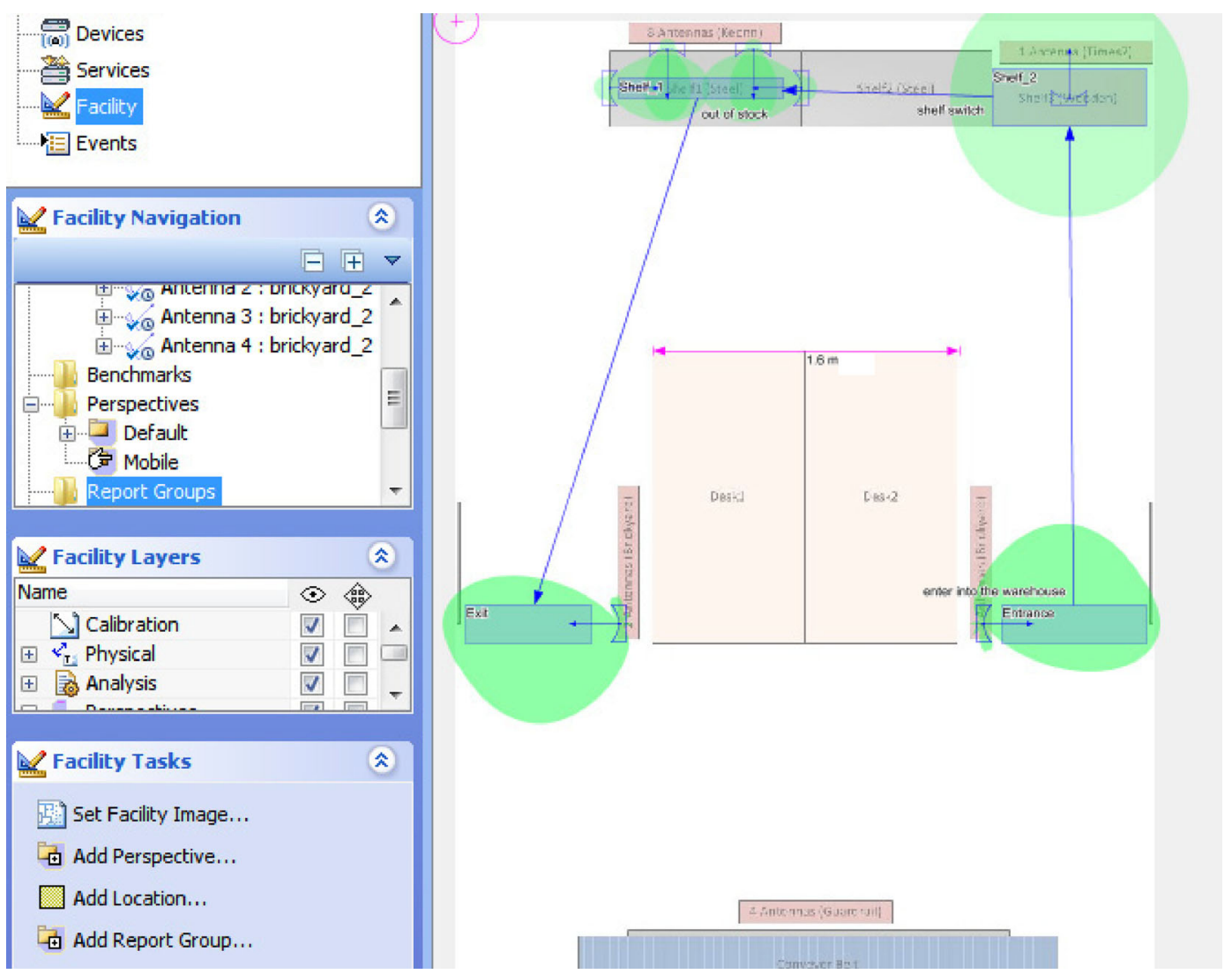

Fig. 11 Facility layout configuration in the middleware management console 


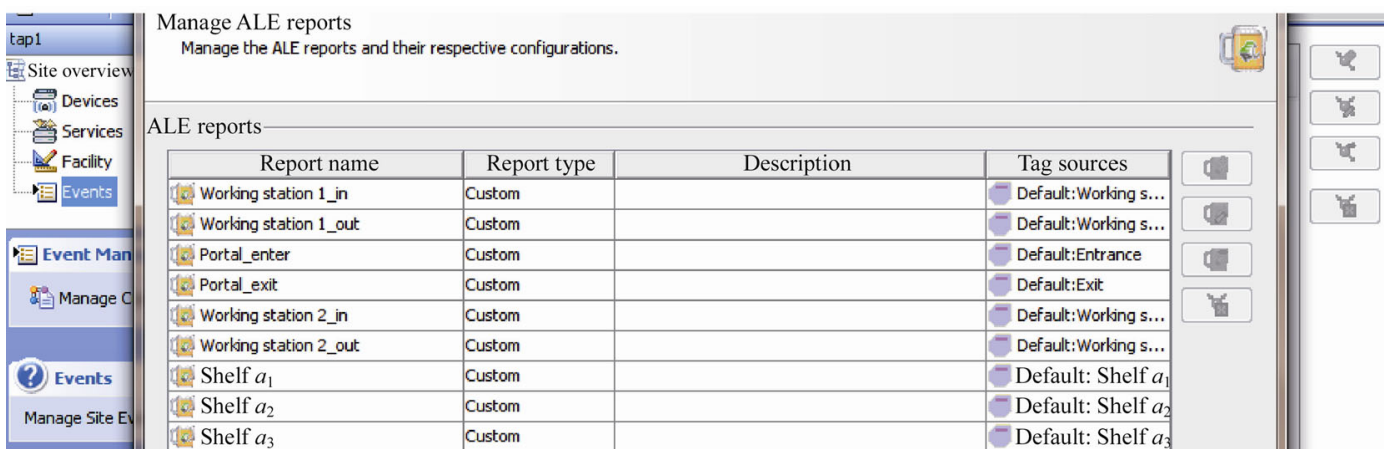

Fig. 12 RFID data report management

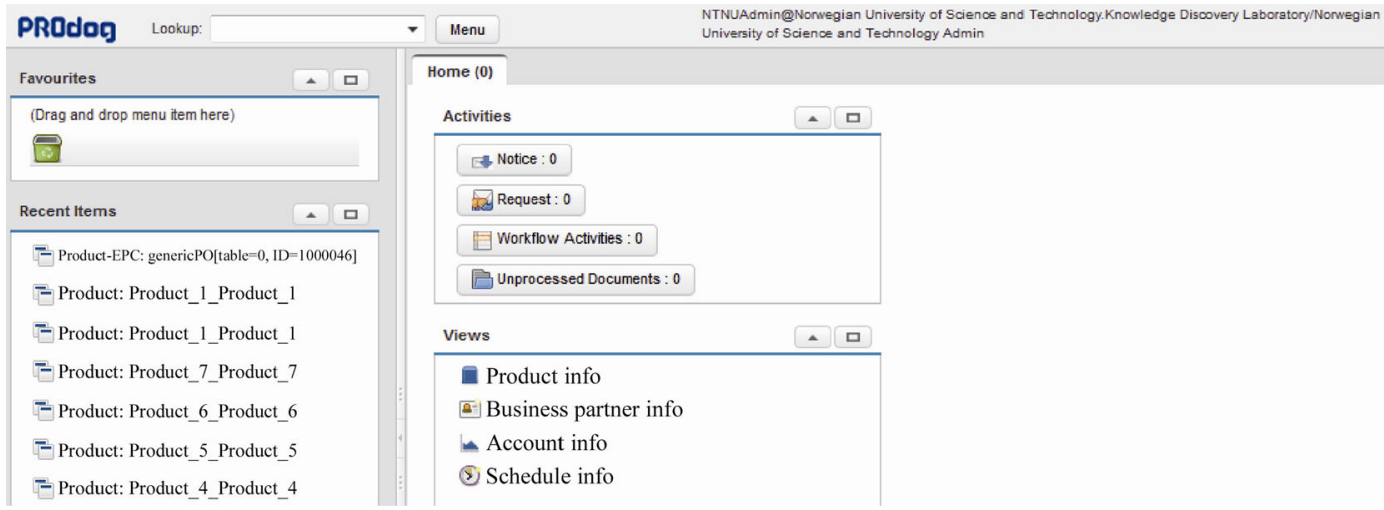

Fig. 13 PROdog user interface

read data from the RFID database and support production management in RFID lab.

Figure 13 shows the user interface of PROdog. PROdog uses a RFID database which is setup locally. Moreover, PROdog is designed to be a cloud based program so that it can be used anywhere as soon as the internet connection is available. This feature makes remote management available.

\subsection{Communication between hardware and software}

As introduced in the previous sections, the II-RFID system is built up on the basis of the RFID tag, reader and the middleware. Figure 14 shows the architecture of the hardware and software. The RST is used to configure readers and get access to the RFID tags; RFID management console is to configure the middleware, manage multiple readers and organize the RIFD data; and the production management software PROdog is used to access the RFID database and support the production management function. The RFID data collected within the RFID network is stored in the database, and input into the PROdog for the production management.

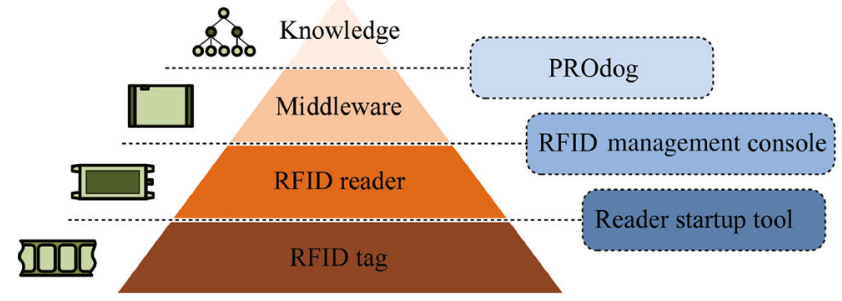

Fig. 14 Architecture of the hardware and software

\section{PROdog in II-RFID framework}

PROdog is RFID-based production management system software, which is especially designed for a production oriented company. PROdog provides a comprehensive shop floor information management solution, as illustrated in Fig. 15. By integrating RFID technology, network techniques, and industrial engineering methodology with the production environment, PROdog can achieve a non-contact manpower saving for supervising management. II-RFID management system can help the manager acquire more production information and determine the 

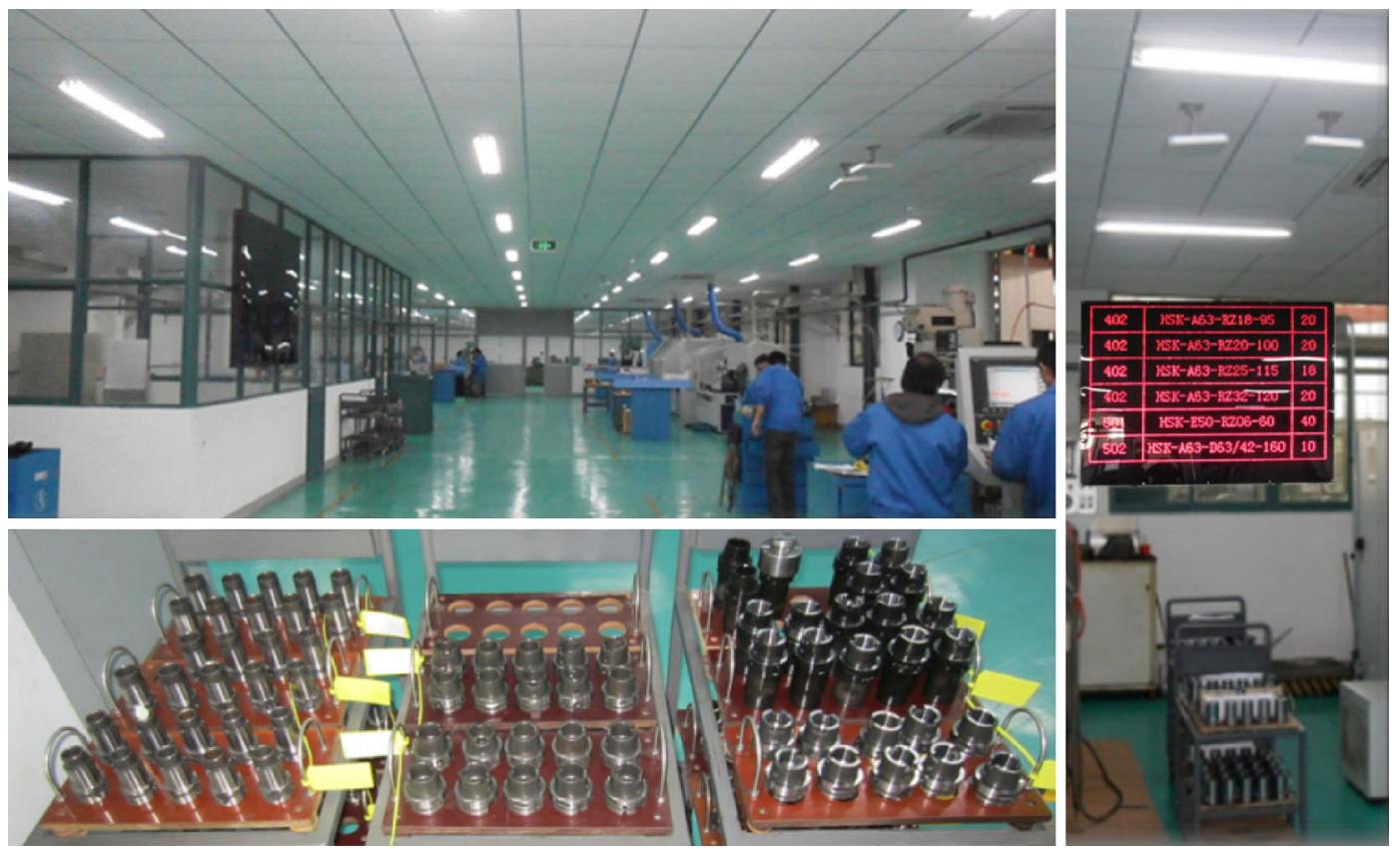

Fig. 15 Production oriented application of PROdog

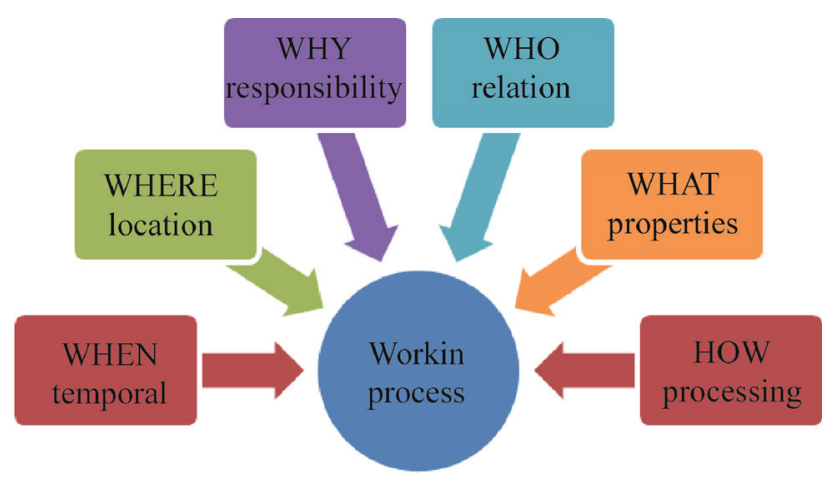

Fig. 16 Using PROdog for the WIP

management tool and method. The WIP information can be recorded and managed. Thus, the production information is available for managers to achieve real-time control and the production process optimization.

\subsection{Introduction of PROdog}

As described above, PROdog mainly focuses on production rather than the enterprise-level manufacturing system. The production process includes the consumption of raw and auxiliary materials. RFID production assistant management system consists of data acquisition, data storing, analysing and management. As shown in Fig. 16, it is used to manage the product in WIP process.

The production management in PROdog consists of several parts, as shown in Fig. 17.
The management function in PROdog is mainly based on four parts, including product management, engineering management, manufacturing flows management and the data based statistical analysis.

(i) The product management comprises the setup and configuration of the product. In PROdog, "Products" is a term used for something procured or sold. These products include items sold to customers, products used in the manufacturing of items that are sold to customers, and components that are purchased by an organization.

(ii) The engineering management includes managing the resource type and the correspondence between resources and EPCIS reports.

(iii) The manufacturing workflows management comprises workflow setup and editing, as well as the BOM editing.

(iv) The statistical analysis comprises product track and query, statistics of the output of both work centre and work station.

\subsection{Application of PROdog}

PROdog is applied in the KDL. Hardware middleware is used to forward the RFID information to the database, which is built on the basis of POSTGRESQL. As described above, eight read points are assigned at three functional areas. RFID data gathered at each read point are stored in the database for PROdog from which real-time production 


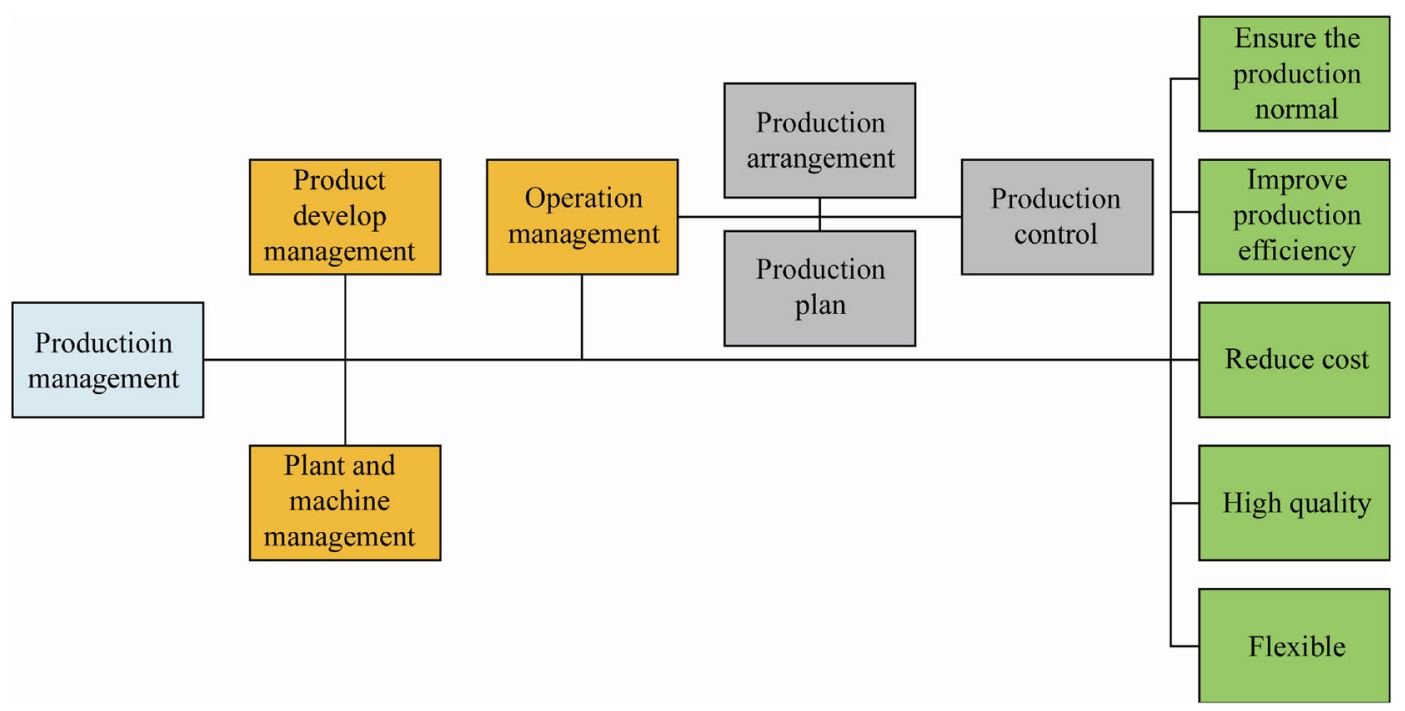

Fig. 17 Production system architecture in PROdog

Get history data of product, main including: when, where, what, why

Client

Organization

Product EPC urn:epc:id:sqtin:0000002.800001.100000010 Product name Pallet 10

Event time: $\quad 8 / 13 / 13$ 3:41 PM

ACTION: Enter

Business location: Prduction line

Business location URI: Productioin line

Read point:

working station 1

Read point URI: Working statioin 1

Busuness step:

urn: epcglobal: cbv:bizxstep:receiving Disposition:

Null

Fig. 18 Product track report generated in PROdog
Client: Norwegian University of Science and Technology
Organization:
urn:epc:id:sqtin:0000002.800001.100000004

Product name: Product_3

Workflow name: Null

Responsible person: Wang Er

Unqualified reason: drawback
Reqister data: $\quad 1 / 22 / 136: 21 \mathrm{PM}$

Workflow node name: Null

Inspector name: YU Quan

Fig. 19 Product quality track report generated in PROdog

information is available, e.g., the product can be tracked according to history data in the form of reports, as shown in Figs. 18 and 19.

Regarding tracking a single RFID tag in the PROdog system, in the RFID management console (RMC), multiple read points are defined on the basis of RFID antennas, as shown in Fig. 20. Moreover, the EPCIS report is defined at each read point, which includes the information according to the EPCIS rules, e.g., business location, business step, disposition, and read point. This information will be sent together with the RFID tag ID to PROdog in the form of EPCIS report.

Furthermore, the keywords in the EPCIS report are extracted by PROdog automatically, as shown in Fig. 21. 

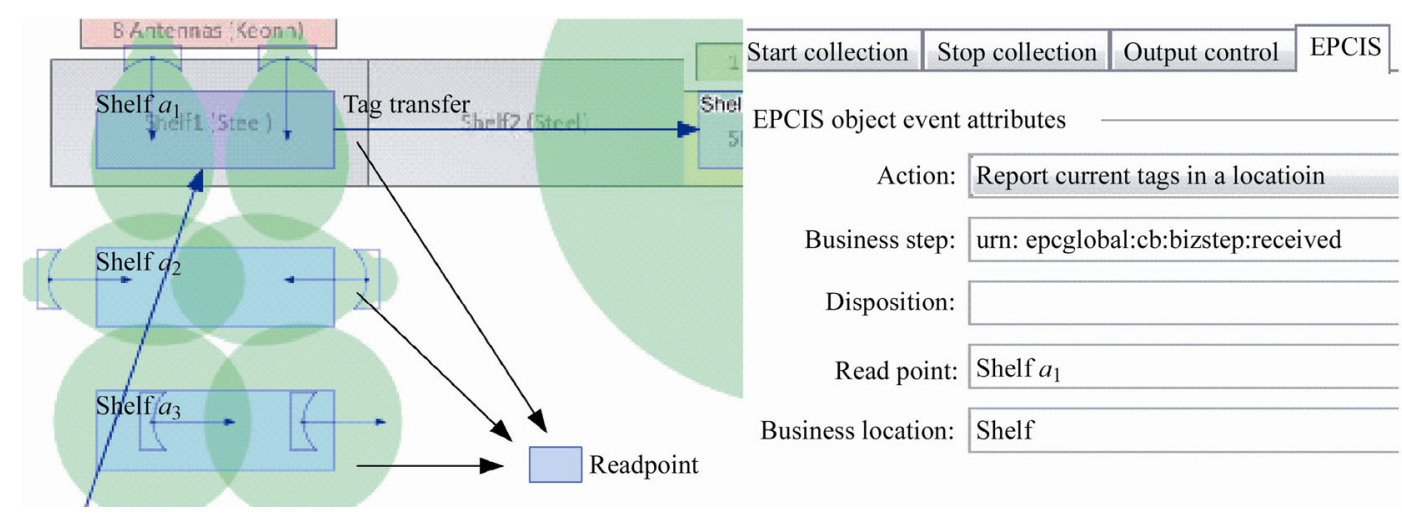

Fig. 20 Definition of the read points and EPCIS attributes in RMC

\begin{tabular}{|c|c|c|c|}
\hline \multirow{2}{*}{\begin{tabular}{|c|}
\multicolumn{2}{r}{ Read point } \\
Client
\end{tabular}} & \multicolumn{3}{|c|}{$14<1 / 8 \rightarrow \mathbf{M}$} \\
\hline & Organization & Active & URI \\
\hline System & $*$ & $\nabla$ & Working_station_1 \\
\hline System & * & $\nabla$ & Portal_exit \\
\hline System & $*$ & $\nabla$ & Portal_enter \\
\hline System & $*$ & $\nabla$ & Shelf $a_{3}$ \\
\hline System & * & $\nabla$ & Shelf $a_{2}$ \\
\hline System & $*$ & $\nabla$ & Shelf $a_{1}$ \\
\hline System & $*$ & $\nabla$ & Shelf $b$ \\
\hline System & $*$ & च & Working_station_2 \\
\hline
\end{tabular}

Fig. 21 Recognition of read points in PROdog

\begin{tabular}{|l|c|}
\hline Product EPC & Product \\
\hline urn:epc:raw:96.69943688227704124629712935431 & Pallet \\
\hline urn:epc:id:sgtin:000002.800001.100000009 & Standard \\
\hline urn:epc:id:sgtin:000002.800001.100000008 & Pallet_2 \\
\hline urn:epc:tag:sgtin-96:3.0000002.800001.100000009 & Shirt \\
\hline
\end{tabular}

Fig. 22 Product-EPC correspondence in PROdog

Meanwhile, the product-EPC correspondence is predefined in PROdog, as shown in Fig. 22. Thus, as soon as the RFID tag enters into the RFID network, its location will be acquired real-time in PROdog.

The EPCIS report works as a bridge between the middleware software and the ERP system-PROdog, as shown in Fig. 23.

Thus, the tagged products will be automatically registered when entering or leaving a working station. Products

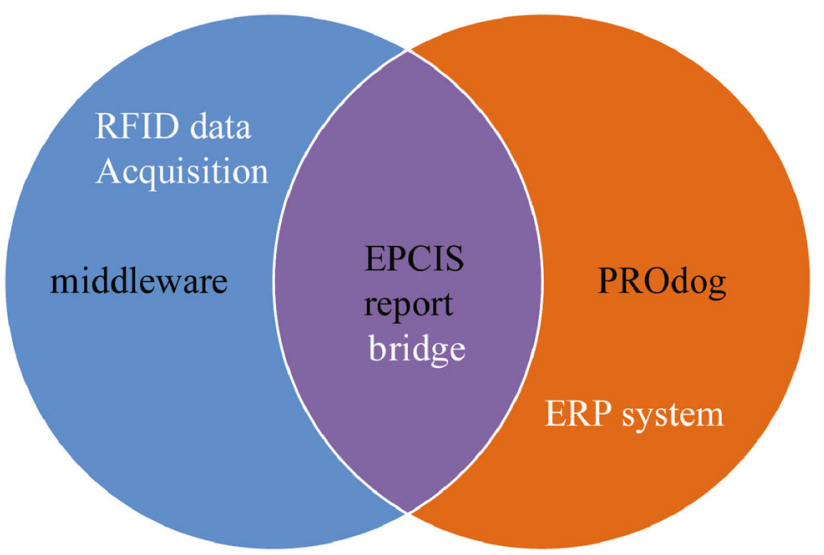

Fig. 23 Combination of the middleware software and the ERP software

can be traceable within a short time, which improves information flow and production efficiency.

\section{Integrating RFID with enterprise information systems in manufacturing}

For years, manufacturers have made investments in providing production with supply chain information that depends on optimizing inventory. RFID provides a method to close some functional gaps particularly related to tracking and genealogy, and compliance management. A combination of RFID investments and incremental, but functionally focused MES applications such as scheduling, can quickly and cost-effectively deliver functionality that parallels comprehensive MES solutions [22].

RFID has the potential of complementing MES in terms of providing new streams of real-time data. RFID information can be used to ensure that the correct labour, machine, tooling, and components are available and ready to use at each processing step, thereby eliminating 


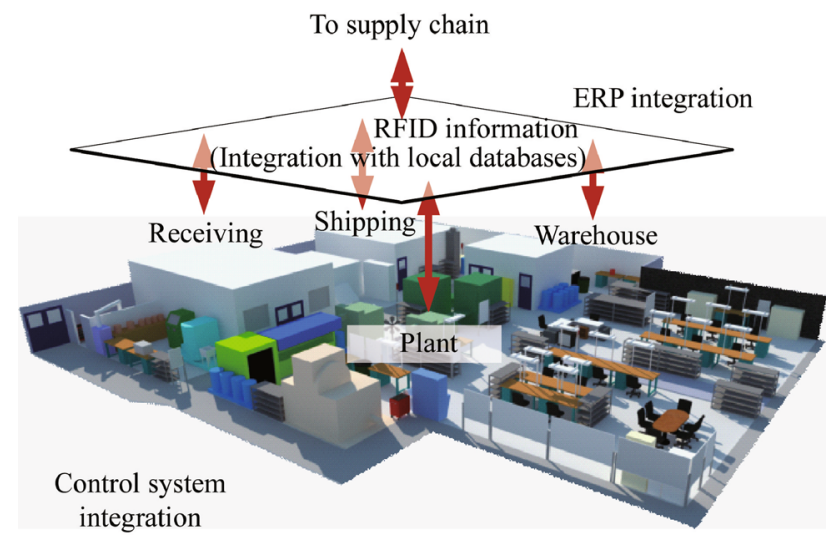

Fig. 24 Manufacturing and assembling information acquisition system with RFID

paperwork and reducing downtime. Furthermore, process steps could be controlled, modified, and even reconfigured in real-time as inbound materials, parts and assemblies move through manufacturing.

Tagging assets provides information about its location, usability status, maintenance requirements, contents, inventory levels, and so on. Devising production steps, maintenance, labour schedules based on this information can help optimize asset performance, and maximize asset utilization. Tagging reusable assets such as machines, fork trucks, tools, fixtures and material handling devices is one of the easiest ways for companies to test RFID in a closed loop environment.

Inventory tracking and visibility is directly related to information management. The better a manufacturer is able to collect, manage, and use information to drive production assets and processes, the more visibility it can provide to its trading partners. RFID could be used in varying scales, either locally or across the entire facility to provide visibility into incoming raw materials, WIP, production sequencing, packaging, palletizing, and warehousing operations, as well as final shipping to the next destination in the supply chain.

RFID can complement existing MES efforts in genealogy tracking. MES for the most part is already collecting information such as product ID, time stamp, physical attributes, machine, order numbers and lot number at each step of the processing. This information can be encoded onto an RFID tag and then passed downstream into the warehouse at a pallet level, and then put out into the supply chain, greatly enabling the ability for a manufacturer to retrace steps in a product recall, as shown in Fig. 24.

Manual intervention is required in many bar coding activities for capturing data. An immediate impact of RFID is eliminating those requirements, thereby freeing up labour to perform more value-added tasks. Effective deployment of RFID also has the potential to quickly provide accurate and reliable data that exceed the bar coding or manual capabilities available today. Information management is critical in how RFID-enabled information can be used to link man/machine tasks, gain visibility into labour usage and productivity, setting the stage for redistribution of related tasks and processes. As shown in Fig. 25, RFID can impact critical performance issues for all manufacturers including machine performance, line performance, plant performance and ultimately, supply chain performance, etc.

\section{Discussions}

There are some challenges of deploying RFID in manufacturing industries for example the technology is still not yet widely understood or installed in the supply chain, and cost/ROI models are far from established. Many companies are therefore now faced with a difficult choice in deciding whether they should be looking at RFID now, or waiting until deployment is more widespread. There is a strong temptation to get carried away by all the hype and publicity surrounding RFID today, which is all the more reason to have a sense of reality as to what it means to integrate RFID, why your company would want to do it, and what would be the acceptable time frames for the perceived benefits. Investing in RFID on the scale required for the supply chain will be a very cost exercise, and if not managed correctly could lead to unnecessary losses. The technology does not plug and play, and will have to be adapted to each application.

Furthermore, implementing an infrastructure to support EPC data could have a considerable impact on existing IT systems. When we integrate RFID system with existing ERP, MES, and WMS systems, it is important to work together with application system providers to obtain optimal solutions. Even though numerous limitations and unresolved issues still hinder the widespread application of RFID, it can be already seen that enterprises in complex supply chains will especially benefit from RFID, once the application difficulties are overcome.

Through the practice of II-RFID system in KDL, we found that two reasons dominate companies' interest in RFID: (i) they expect their customers to demand RFID solutions in the future, and they want to be prepared for this; (ii) specific customers' demands and the need to obtain competitive advantages motivate the companies to improve the tracking of their production processes. The benefits of applying RFID technology will support manufacturing companies to have the ability of traceability and visualization.

RFID technology can be used in the following seven application areas in manufacturing including accelerating scan processes, extending scan processes for quality and 


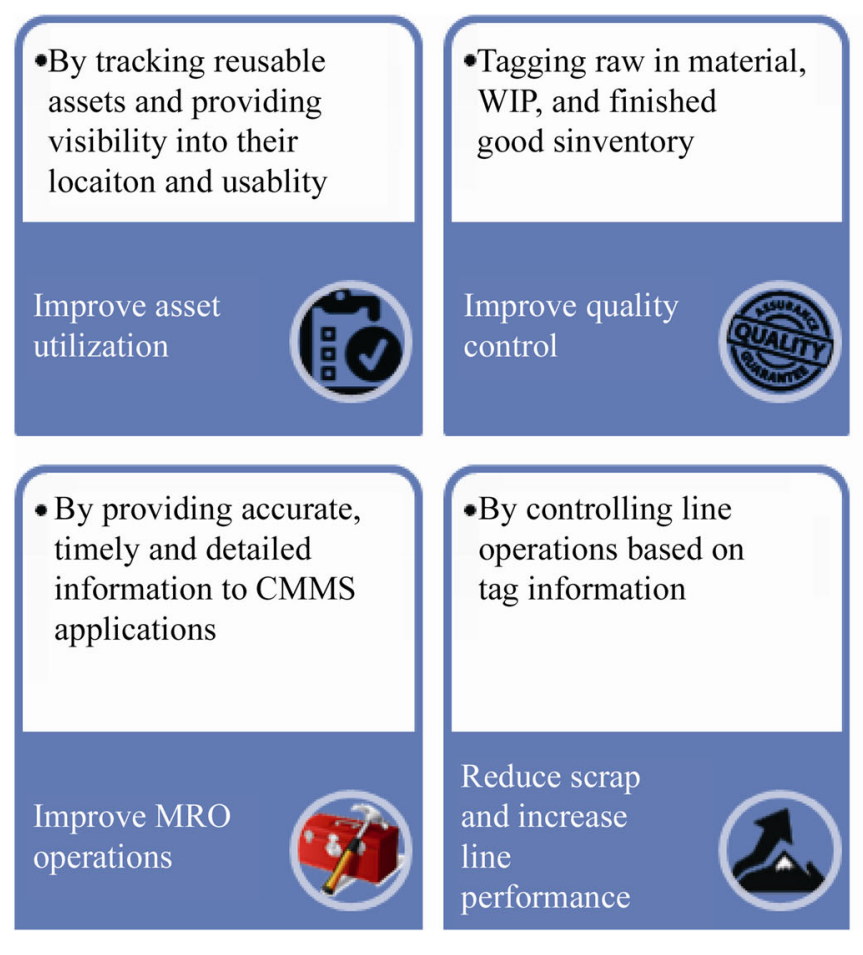

Fig. 25 Benefits of applying RFID in manufacturing

efficiency, extending scan processes for narrowing recalls, reducing paper-based data management, automating asset tracking, reducing back-end interactions, and unifying labels.

As we discussed, deploying RFID in manufacturing industries can support the advantages of traceability and visualization, but it also generates large datasets which need suitable analysis methods to allow a comprehensive understanding of the relationships between products and behavioral patterns (or rules). This challenge can be solved by advanced DM algorithms. The future research areas in developing IIRFID system will be focused on data collection and processing, data management, event processing, and DM.

\section{Conclusions}

This paper gave an overview of the current state and trends of RFID technology, the principle and standards of RFID system, and the framework of II-RFID system. We have presented two scenarios: one is to show how the system is developed and implemented in KDL including the hardware connection and software configuration; and the other is how to apply PROdog in II-RFID system for shop floor management. The proposed II-RFID system provides a theoretical guidance to enhance the traceability of products in the manufacturing chain. The demonstration in KDL verifies the feasibility of the system framework, which can
- Provide accurate, timely, and detailed information to ERP and MES
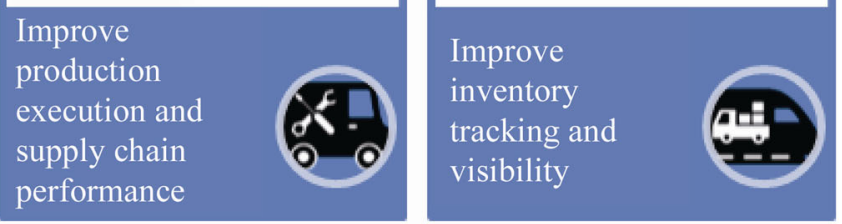

-With complete tracking, verification and validation of processes

\section{Support 21 CFR}

part 11

compliance
-With real-time tracking and automatic synchronization

By collecting historical information at each step of manufacturing process and across supply chain

Deliver surgical

precision in

product tracking and genealogy

be considered as a reference for the practical industry manufacturing.

The next step of the development II-RFID system will be to develop some models of DM for analyzing and solving specific manufacturing problems, such as flow mining and route mining.

\section{References}

1. Chryssolouris G et al (2009) Digital manufacturing: history, perspectives, and outlook. J Eng Manuf 223(5):451-462

2. Jr Quirk RE (2007) RFID's new challenge. Traffic World 271(12):19-21

3. Wang K, Yu Q, Ricke K (2013) Feasibility study of RFID (radio frequency identification) for Hansen protection AS. SINTEF report, No. A24703, ISBN: 9788214056105, Trondheim

4. Gunther O, Kletti W, Kubach U (2008) RFID in manufacturing. Springer, Berlin

5. Laniel M, Emond JP, Altunbas AE (2008) RFID behavior study in enclosed trailer/container for real time temperature tracking. In: Food processing automation conference, Providence, Rhode Island, USA

6. Abad E, Palacio F, Nuin M et al (2009) RFID smart tag for traceability and cold chain monitoring of foods: demonstration in an intercontinental fresh fish logistic chain. J Food Eng 93(4):394-399

7. Lewis S (2004) A basic introduction to RFID technology and its use in the supply chain. Laran RFID, White Paper

8. Emond JP, Nicometo M (2006) Shelf-life prediction and FEFO inventory management with RFID. In: The cool chain association workshop: temperature measurements when, where and how? Knivsta, Sweden 
9. Koutsoumanis K, Taoukis PS, Nychas GJE (2005) Development of a safety monitoring and assurance system for chilled food products. Int J Food Microbiol 100(1-3):253-260

10. Saygin C, Sarangapani J, Grasman SE (2007) A systems approach to viable RFID implementation in the supply chain. Springer series in advanced manufacturing, pp 3-27

11. Cabanes G, Bennani Y, Chartagnat C et al (2008) Topographic connectionist unsupervised learning for RFID behavior data mining. In: Proceedings of the 2nd international workshop on RFID technology - concepts, applications, challenges, IWRT 2008, pp 63-72

12. El-Sobky H, AbdelAzeim M (2011) A novel model for capturing and analyzing customers' references for ceramic tiles, secondary a novel model for capturing and analyzing customers' references for ceramic tiles, pp 460-465

13. Ho GTS, Choy KL, Poon TC (2010) Providing decision support functionality in warehouse management using the RFID-based fuzzy association rule mining approach. In: Proceedings of 2010 8th international conference on supply chain management and information systems (SCMIS), Hong Kong, China

14. Masciari E (2011) Trajectory outlier detection using an analytical approach. In: 23rd IEEE international conference on tools with artificial intelligence (ICTAI), 2011, pp 377-384

15. Huang GQ, Wright PK, Newman ST (2009) Wireless manufacturing: a literature review, recent developments, and case studies. Int J Comput Integr Manuf 22(7):579-594
16. Mo JPT et al (2009) Directional discrimination in radio frequency identification system for materials flow control in manufacturing and supply chain. Proc Inst Mech Eng B 223(7):875-883

17. Brintrup A, Ranasinghe D, McFarlane D (2010) RFID opportunity analysis for leaner manufacturing. Int J Product Res 48(9): $2745-2764$

18. Ren Z, Anumba CJ, Tah J (2010) RFID-facilitated construction materials management (RFID-CMM) - a case study of watersupply project. Adv Eng Inf 25(2):198-207

19. Huang GQ et al (2008) RFID-enabled real-time wireless manufacturing for adaptive assembly planning and control. J Intell Manuf 19(6):701-713

20. Yu Q, Wang Y, Wang K (2012) Extracting associative rules for RFID data. In: Proceedings of IWAMA 2012 (international workshop of advanced manufacturing and automation). Tapir Academic Publisher, Trondheim, pp 467-474

21. Wang K, Yu Q, Wang Y (2013) RFID based data mining for E-logistics. In: ICE-B 2013 (intentional conference of e-business), 29-31 July, 2013, Reykevik, Iceland

22. Rockwell Automation (2004) RFID in manufacturing-a practical guide on extracting measureable value from RFID implementations in plant and warehouse operation. (www.rockwellautomation.com) 